\title{
Effect of Sodium Fluoride on Bone Biomechanical and Histomorphometric Parameters and on Insulin Signaling and Insulin Sensitivity in Ovariectomized Rats
}

\author{
Rita de Cássia Alves Nunes ${ }^{1}$ - Fernando Yamamoto Chiba ${ }^{2}$ - Amanda Gomes Pereira ${ }^{1}$. \\ Renato Felipe Pereira $^{1} \cdot$ Maria Sara de Lima Coutinho Mattera ${ }^{1} \cdot$ Edilson Ervolino $^{1}$. \\ Mário Jefferson Quirino Louzada ${ }^{3}$ - Marília Afonso Rabelo Buzalaf ${ }^{4}$ • \\ Cristina Antoniali Silva ${ }^{1}$. Doris Hissako Sumida ${ }^{1}$
}

Received: 18 November 2015 / Accepted: 4 February 2016/Published online: 15 February 2016

(C) Springer Science+Business Media New York 2016

\begin{abstract}
Osteoporosis is a systemic disease characterized by bone degradation and decreased bone mass that promotes increased bone fragility and eventual fracture risk. Studies have investigated the use of sodium fluoride $(\mathrm{NaF})$ for the treatment of osteoporosis. However, fluoride can alter glucose homeostasis. The aim of this study was to evaluate the effects of $\mathrm{NaF}$ intake $(50 \mathrm{mg} / \mathrm{L})$ from water on the following parameters of ovariectomized (OVX) rats: (1) tyrosine phosphorylation status of insulin receptor substrate (pp185 (IRS-1/IRS-2)) in white adipose tissue; (2) insulin sensitivity; (3) plasma concentrations of glucose, insulin, total cholesterol, triglyceride, TNF- $\alpha$, IL-6, osteocalcin, calcium, and fluoride; (4) bone density and biomechanical properties in the tibia; and (5) tibia histomorphometric analysis. Fifty-two Wistar rats (2 months old) were ovariectomized and distributed into two groups: control group (OVX-C) and $\mathrm{NaF}$ group (OVX-F), which was subjected to treatment with $\mathrm{NaF}(50 \mathrm{mg} / \mathrm{L})$ administered
\end{abstract}

Doris Hissako Sumida

dorishs@foa.unesp.br

1 Ciências Fisiológicas-SBFis, Department of Basic Sciences, Araçatuba Dental School, UNESP-Univ Estadual Paulista, Rua José Bonifácio 1193, Araçatuba CEP 16015-050, Brazil

2 Department of Child and Social Dentistry, Araçatuba Dental School, UNESP-Univ Estadual Paulista, Rua José Bonifácio 1193. Araçatuba CEP 16015-050, Brazil

3 Department of Support, Animal Production and Health, Araçatuba School of Veterinary Medicine, UNESP-Univ Estadual Paulista, Rua Clóvis Pestana, 793., Araçatuba CEP 16050-680, Brazil

4 Department of Biological Sciences, Bauru Dental School, University of São Paulo, Alameda Octávio Pinheiro Brisolla, 9-75, Bauru, São Paulo 17012-901, Brazil in drinking water for 42 days. The chronic treatment with $\mathrm{NaF}$ promoted (1) a decrease in pp185 (IRS-1/IRS-2) tyrosine phosphorylation status after insulin infusion in white adipose tissue and in insulin sensitivity; (2) an increase in the plasma concentration of insulin, fluoride, osteocalcin, calcium, triglyceride, VLDL-cholesterol, TNF- $\alpha$, and IL-6; (3) a reduction in the trabecular width, bone area, stiffness, maximum strength, and tenacity; (4) no changes in body weight, food and water intake, plasma glucose, total cholesterol, HDL-cholesterol, LDL-cholesterol, bone mineral content, and bone mineral density. It was concluded that chronic treatment with $\mathrm{NaF}(50 \mathrm{mg} / \mathrm{L})$ in OVX rats causes a decrease in insulin sensitivity, insulin signaling transduction, and biochemical, biomechanical, and histomorphometric bone parameters.

Keywords Fluoride $\cdot$ Bone density $\cdot$ Osteoporosis · Insulin resistance $\cdot$ Rats

\section{Introduction}

Patients with type 1 diabetes mellitus show a lack of insulin and do not reach the peak of bone mass, leading to a decrease in bone mineral density and an increase in the risk of fractures. On the other hand, patients with type 2 diabetes mellitus show hyperinsulinemia that stimulates bone formation. This can be explained by the fact that insulin is an anabolic factor to the bones [1].

Osteoporosis is defined as a systemic disease affecting the skeleton and is characterized by decreased bone mass and microarchitectural deterioration, with a consequent increase in bone fragility and risk of fracture [2]. 
Several studies have investigated the use of fluoride for the treatment of osteoporosis [3, 4]. Fluoride can accumulate in calcified tissues such as teeth and bones, altering the quality of these tissues $[5,6]$. Researchers have demonstrated that fluoride has osteogenic effects, such as increasing the number of osteoblasts in response to stimulation and proliferation of osteoblast precursors, as well as antiresorptive capacity [7]. Furthermore, studies have demonstrated that fluoride treatment increases bone density; however, it may decrease biomechanical properties. Therefore, the increase in bone mass induced by treatment with $\mathrm{NaF}$ does not necessarily correspond to increased bone strength [8].

Besides influencing bone metabolism, fluoride can also alter glucose homeostasis $[9,10]$. Studies with castrated male rats demonstrated that chronic treatment with $\mathrm{NaF}$ promoted insulin resistance and decreased insulin signaling [11-13]. In addition, chronic treatment with fluoride in castrated rats also increased the IRS-1 serine phosphorylation status in adipose tissue, resulting in the attenuation of insulin signal transduction $[11,13]$.

There is no consensus about the effectiveness of $\mathrm{NaF}$ in promoting the formation of healthy bone [14], and, depending on the dosage, fluoride can promote changes in glycemic homeostasis $[11,13,15]$ and insulin sensitivity [16]. Therefore, the aim of this study was to examine the effect of chronic treatment with $\mathrm{NaF}(50 \mathrm{mg} / \mathrm{L}$ in drinking water) on the insulin sensitivity, insulin signal transduction, and biomechanical and histomorphometric parameters in the bone of ovariectomized $(\mathrm{OVX})$ rats.

\section{Materials and Methods}

\section{Animal Grouping and Treatments}

All experimental procedures were approved by the Institutional Committee on Animal Research and Ethics (Protocol No. 00941-2013). Fifty-two 2-month-old female Wistar rats were kept under a 12/12-h light/dark cycle (lights on at 0700) and room temperature of $21 \pm 2{ }^{\circ} \mathrm{C}$, with free access to a regular laboratory rat diet (Presence ${ }^{\mathbb{R}}$; Evialis Industry of Brazil Ltd., Paulinia, Brazil) and water. Under anesthesia $(80 \mathrm{mg} / \mathrm{kg}$ ketamine and $10 \mathrm{mg} / \mathrm{kg}$ xylazine), bilateral ovariectomies were performed in all the rats. These rats were distributed into two groups: the control group (OVX-C), which was subjected to a solution of $\mathrm{NaCl}(9.54 \mathrm{mg} / \mathrm{kg}$ body weight) containing the same amount of sodium as that received by the $\mathrm{NaF}$ group, and the NaF group (OVX-F; hereafter also referred to as "F-treated rats"), which was treated with $\mathrm{NaF}(50 \mathrm{mg} / \mathrm{L})$ administered in drinking water. During 42 days, the volume of water consumed by each rat in a day in both groups was measured 3 days per week. At the end of this period, the animals from both the OVX-C and OVX-F groups were fasted from food for $14 \mathrm{~h}$ and the OVX-F group was deprived from the NaF solution for $4 \mathrm{~h}$ before the day of the experimental measurements to avoid an acute fluoride effect. Both groups of rats were then anesthetized with sodium thiopental (Thiopentax ${ }^{\circledR}$; Cristália Pharmaceutical Chemicals Ltd., Itapira, Brazil; $3 \%, 5 \mathrm{mg} / 100 \mathrm{~g}$ body weight, intraperitoneally). Ten control and ten F-treated rats were subjected to the intravenous insulin tolerance test $(0.75 \mathrm{U}$ insulin $/ \mathrm{kg}$ body weight). The left tibiae of these same animals were also acquired to evaluate the effect of the treatment with $\mathrm{NaF}$ on the fluoride concentration in the bone, and the right tibiae were used for immunohistochemical analysis. Six control and six F-treated rats were used to quantify the pp185 (IRS-1/IRS-2) tyrosine phosphorylation status in the white adipose tissue after regular human insulin (1.5 U, intravenously) administration. Median laparotomy was performed in ten control and ten F-treated rats, and blood was collected from the inferior vena cava. The plasma samples from these animals were stored at $-70{ }^{\circ} \mathrm{C}$ until quantification of the plasma concentrations of glucose, insulin, total cholesterol (TC), triglyceride (TG), tumor necrosis alpha (TNF- $\alpha$ ), interleukin-6 (IL-6), calcium, and fluoride. The left tibiae of these same animals were also acquired for biomechanical analysis, and the right tibiae were used for histomorphometric analysis.

\section{Evaluation of Bone Mineral Density and Biomechanical Parameters}

The total area $\left(\mathrm{cm}^{2}\right)$, bone mineral content (BMC; $\left.\mathrm{g}\right)$, and bone mineral density (BMD; $\mathrm{g} / \mathrm{cm}^{2}$ ) were measured by whole left tibia dual X-ray absorptiometry (DXA; Lunar DPX Alpha; Lunar Corp., Madison, WI, USA). The biomechanical properties of the tibiae of rats were evaluated by 3-point bending, using a universal testing machine (DL 3000; EMIC ${ }^{\circledR}$, SP, Brazil). Each tibia was loaded centrally in the diaphysis medium, with a support distance range of two thirds of the bone length, and a load cell of $2000 \mathrm{~N}$ was applied at a rate of $5 \mathrm{~mm} /$ min until the bone fractured. The load and displacement of the cross bar of the machine were monitored and recorded using a software program (DL 3000; EMIC ${ }^{\circledR}$, SP, Brazil). From these data, the load-displacement curves were obtained. The maximum load (Fmax) represents the highest load that the bone can support. In fact, it is a precise parameter for directly evaluating the resistance of the bone. The slope of the elastic region of the load-displacement curve is the extrinsic stiffness $\left(\times 10^{3} \mathrm{~N} / \mathrm{m}\right)$ of the structure, and the area under the load-displacement curve (i.e., the area of the elastic strain region plus the area of the plastic strain region) is a measure of the amount of energy required to cause a bone fracture [17]. 


\section{Analysis Methods}

The plasma samples were used for the determination of glycemia by the oxidase glucose method (enzymatic glucose; ANALISA Diagnóstica, Belo Horizonte, MG, Brazil) and insulinemia by the radioimmunoassay method (Coat-aCount, DPC; Diagnostic Products, Los Angeles, CA, USA). Insulin resistance was evaluated from the homeostasis model assessment of insulin resistance (HOMA-IR) index, calculated using the following formula: HOMA-IR = fasting glycemia $(\mathrm{mmol} / \mathrm{L}) \times$ fasting insulinemia $(\mu \mathrm{UI} / \mathrm{mL}) / 22.5$ [18]

\section{Determination of TNF- $\alpha$}

Blood samples were collected from the inferior vena cava to measure the plasma TNF- $\alpha$ concentration. After centrifugation, the supernatant was collected and maintained at $-70{ }^{\circ} \mathrm{C}$ until use. A 96-well plate was coated with a monoclonal antibody to TNF- $\alpha$. Samples and recombinant TNF- $\alpha$ were added to the wells, and, after $2 \mathrm{~h}$, unbound proteins were washed away and an enzyme-linked polyclonal antibody was added to the wells; this antibody acted as a link between TNF- $\alpha$ and the dye, whereby a color change proportional to the amount of TNF- $\alpha$ was observed. This color change was quantified by comparing the optical densities of the samples with those of known dilutions, using a plate reader at $450 \mathrm{~nm}$. The concentration of TNF- $\alpha$ was calculated from a standard curve, in units of picogram/milliliter.

\section{Determination of IL-6}

The concentration of plasma IL-6 was determined by ELISA, using a commercial kit specific for rats according to the manufacturers' instructions (BD Biosciences, San Diego, USA; and Biovedor, Heidelberg, Germany).

\section{Determination of Osteocalcin}

The concentration $(\mathrm{pg} / \mathrm{mL})$ of plasma osteocalcin was determined by ELISA, using a commercial kit specific for rats according to the manufacturer's instructions (USCN Life Science Inc., Houston, TX, USA).

\section{Determination of Triglyceride, Total Cholesterol, High-Density Lipoprotein Cholesterol, Low-Density Lipoprotein Cholesterol, and Very Low-Density Lipoprotein Cholesterol Levels}

Blood samples were collected from the inferior vena cava to measure the plasma concentrations of TG, TC, and highdensity lipoprotein cholesterol (HDL-C). After centrifugation, the supernatant was collected and stored at $-20{ }^{\circ} \mathrm{C}$ until use. Plasma concentrations of TG, TC, and HDL-C were measured using an enzymatic colorimetric method (Labtest Diagnostica S.A., Lagoa Santa, Minas Gerais, Brazil), using a spectrophotometer at wavelengths of 505, 500, and $500 \mathrm{~nm}$, respectively.

The levels of low-density lipoprotein cholesterol (LDL-C) and very low-density lipoprotein cholesterol (VLDL-C) were determined from the values obtained for TG, TC, and HDL-C, using the Friedewald equation [19].

\section{Determination of Fluoride Ion Concentration in Blood Plasma}

For analysis of the fluoride ion level in plasma, pre-diffusion with heated hexamethyldisiloxane (HMDS)- $\mathrm{H}_{2} \mathrm{SO}_{4}$ was done to remove $\mathrm{CO}_{2}$. The fluoride ion concentration in plasma was determined after $12 \mathrm{~h}$ of diffusion facilitated by the HMDS [20], as modified by Whitford [21], using a fluoride ionselective electrode (Model 9409; Orion Research, Cambridge, MA, USA) and a calomel reference microelectrode (\#13-620-79; Accumet) coupled to a potentiometer (Model EA 940; Orion Research), as described by Buzalaf et al. [22].

\section{Determination of Fluoride Ion Concentration in Tibiae}

Bone fluoride ion levels were measured by direct potentiometry, using an ion-selective electrode (Orion 9409; Orion Research), after isothermal distillation [23]. Prior to the measurements, the bone tissue was incinerated for $6 \mathrm{~h}$ at $550{ }^{\circ} \mathrm{C}$.

\section{Determination of Calcium Levels}

Calcium measurements were performed by a spectrophotometric method, using a commercial kit according to the manufacturer's instructions (Labtest Diagnóstica S.A.).

\section{Short Intravenous Insulin Tolerance Test}

The intravenous insulin tolerance test (ITT) was carried out on ten animals of each group (OVX-C and OVX-F) as follows. The test was performed with the animals anesthetized as described in the section "Animal Grouping and Treatments." Cannulation of the right jugular vein was conducted, introducing the sylastic cannula in proximity to the atrium (superior vena cava). This cannula served as the venous access for injection of insulin, which was administered at a dose of $0.75 \mathrm{U} /$ $\mathrm{kg}$ body weight. Blood samples $(50 \mu / \mathrm{L})$ were collected from nicked tails at 0 (before hormone administration), 4, 8, 12, and 16 min after insulin administration, and the glucose level was measured using a glycemia monitor (ACCU-CHEK Advantage; Roche Diagnostics, Indianapolis, IN, USA). The results were analyzed by comparison of the rate constant for glucose disappearance ( $K_{\text {itt }}$ value) from 0 to 16 min of the test. 
The $K_{\text {itt }}$ value was calculated using the equation $0.693 / t_{1 / 2}$. The glucose $t_{1 / 2}$ value was calculated from the slope of the least-square analysis of the plasma glucose concentrations during the linear-decay phase [24].

\section{Evaluation of the Tyrosine Phosphorylation Status of the Insulin Receptor Substrate}

Samples of white adipose tissue were collected from six animals of each group (OVX-C and OVX-F) before and after $(120 \mathrm{~s})$ the administration of $1.5 \mathrm{U}$ of regular insulin. Tissue samples were prepared according to the method described by Carvalho et al. [5] and subjected to the western blot assay for quantification of the pp185 (IRS-1/IRS-2) tyrosine phosphorylation status, using the anti-phosphotyrosine antibody (Santa Cruz Biotechnology, Santa Cruz, CA, USA). Immunoreactive bands were detected by autoradiography, using a chemiluminescent substrate system (Santa Cruz Biotechnology) according to the instructions of the manufacturer. Quantitative analysis of the blots was performed by using an image analysis software (NIH Image v.b3b; National Institutes of Health, Bethesda, MD, USA) [24].

\section{Histomorphometric Analysis}

For histomorphometric analysis, ten animals from each group were used. The right tibia was collected and fixed in $4 \%$ formaldehyde for $24 \mathrm{~h}$. Decalcification was performed in Plank-Rychlo's solution. Specimens were routinely processed, embedded in paraffin, and sectioned longitudinally. Semi-serial sections (5- $\mu \mathrm{m}$ thickness) of the right tibia were obtained and stained with hematoxylin and eosin. Three equidistant sections from the center of the bone were selected from each specimen and imaged using a digital camera coupled to a light microscope. The cancellous bone compartment of the tibial proximal metaphysis was analyzed. This analysis was performed in the center of the metaphysis with a $\times 200$ magnification in an area of $840 \mu \mathrm{m} \times 560 \mu \mathrm{m}$ located at $1 \mathrm{~mm}$ below the growth plate. Analysis was carried out using the ImageJ public domain image analysis system. The following bone histomorphometric parameters were measured: percentage of cancellous bone in the area analyzed; B.Ar, cancellous bone area $\left(\mathrm{mm}^{2}\right)$; Tb.N, trabecular number per $\mathrm{mm}^{2}$; and $\mathrm{Tb} . \mathrm{Wi}$, trabecular width $(\mu \mathrm{m})$. All nomenclature, symbols, and units for bone histomorphometry were expressed as recommended by the American Society for Bone and Mineral Research Histomorphometry Nomenclature Committee [25].

\section{Immunohistochemistry}

The slides were separated and destained for immunohistochemical analysis. Endogenous peroxidase activity was inhibited with hydrogen peroxide, antigen recovery was obtained with citrate buffer at $60{ }^{\circ} \mathrm{C}$ for $20 \mathrm{~min}$, and nonspecific reactions were blocked with defatted milk and bovine serum albumin during the antibody incubation.

Primary antibodies against tartrate-resistant acid phosphatase (Code SC 30832; Santa Cruz Biotechnology), a biotinylated secondary antibody (Pierce Biotechnology), streptavidin biotin amplifier (Dako, Denmark), and diaminobenzidine (Dako, Denmark) as the chromogen (which gives a brown color to the markings) were used. At the end of the reactions, the slides were counterstained with Harris hematoxylin. The intensity of the immunoreaction was scored as 0 - absent, 1 weak, 2-moderate, and 3-intense [26]. To perform the analysis, an optical microscope with a magnification objective of $\times 160$ (Leica Aristoplan Microsystems; Leitz, Benshein, Germany) was used, coupled to an image-capturing camera (Leica DFC 300FX; Leica Microsystems, Heerbrugg, Switzerland) and connected to a Pentium III microcomputer loaded with digitized image analyzer software (Leica Camera Software Box, Leica Imaging Manager, IM50 Demo Software).

\section{Statistical Analysis}

Statistical analyses of insulin signaling were performed by using analysis of variance, followed by Tukey's post hoc test when the analysis of variance suggested a significant difference between groups $(p<0.05)$. The Student's $t$ test was performed for the analysis of $K_{\text {itt }}$ values; plasma glucose, insulin, TC, TG, TNF- $\alpha$, IL-6, osteocalcin, calcium, and fluoride concentrations; and biomechanical properties in the tibia. Statistical analysis of immunohistochemistry was performed by the Mann-Whitney test. The value of $p<0.05$ was considered statistically significant. Data analysis was performed with a statistical program (GraphPad Prism version 5.0).

\section{Results}

\section{Biochemical Parameters}

As shown in Table 1, the OVX-F group exhibited no changes in plasma glucose concentration, but there was a significant increase $(p<0.05)$ in plasma insulin concentration. From these values, the HOMA-IR index was calculated, as described in the section "Analysis Methods." It was found that the HOMA-IR index was significantly higher $(p<0.05)$ in the OVX-F group.

The OVX-F group showed a glucose disappearance rate $\left(K_{\text {itt }}\right.$ value) that was significantly lower $(p<0.05)$ than that of the OVX-C group. Additionally, the OVX-F group showed increased plasma concentrations of calcium, osteocalcin, fluoride, IL-6, TNF- $\alpha$, TG, and VLDL-C compared with the OVX-C group. However, the treatment with $\mathrm{NaF}$ did not 
Table 1 Plasma concentrations of glucose, insulin, fluoride, IL-6, TNF- $\alpha$, calcium, osteocalcin, triglyceride, total cholesterol, high-density lipoprotein cholesterol, low-density lipoprotein cholesterol, and very lowdensity lipoprotein cholesterol, as well as $K_{\mathrm{itt}}$ and HOMA-IR values in control and test ovariectomized rats

\begin{tabular}{lll}
\hline Parameters & OVX-C & OVX-F \\
\hline Glycemia $(\mathrm{mmol} / \mathrm{L})$ & $06.86 \pm 0.18$ & $06.77 \pm 0.23$ \\
Insulinemia $(\mu \mathrm{U} / \mathrm{mL})$ & $10.83 \pm 2.11$ & $18.03 \pm 1.79^{*}$ \\
$K_{\text {itt }}(\% / \mathrm{min})$ & $03.80 \pm 0.80$ & $01.90 \pm 0.30^{*}$ \\
IL-6 $(\mathrm{pg} / \mathrm{mL})$ & $28.70 \pm 0.58$ & $32.71 \pm 1.64^{*}$ \\
TNF- $\alpha(\mathrm{pg} / \mathrm{mL})$ & $6.00 \pm 0.19$ & $6.97 \pm 0.41^{*}$ \\
Calcium $(\mathrm{mg} / \mathrm{dL})$ & $9.57 \pm 0.15$ & $10.49 \pm 0.15^{*}$ \\
Osteocalcin $(\mathrm{pg} / \mathrm{mL})$ & $52.08 \pm 7.51$ & $110.70 \pm 20.0^{*}$ \\
Fluoride $(\mu \mathrm{g} / \mathrm{mL})$ & $0.04 \pm 0.01$ & $0.14 \pm 0.02^{*}$ \\
HOMA-IR & $3.30 \pm 0.64$ & $5.62 \pm 0.51^{*}$ \\
Total cholesterol & $90.98 \pm 2.71$ & $92.85 \pm 3,29$ \\
Triglyceride & $88.63 \pm 2.93$ & $99.80 \pm 3.93^{*}$ \\
HDL-C & $45.21 \pm 0.73$ & $45.54 \pm 1.03$ \\
VLDL-C & $17.73 \pm 0.58$ & $19.96 \pm 0.78^{*}$ \\
LDL-C & $28.95 \pm 2.72$ & $26.00 \pm 3.08$ \\
\hline
\end{tabular}

Results are expressed as the mean $\pm \mathrm{SEM}, n=10 .{ }^{*} p<0.05$ compared with the control group

$O V X-C$ ovariectomized rats administered an equivalent amount of sodium ions only, $O V X-F$ ovariectomized rats treated with $50 \mathrm{mg} / \mathrm{L}$ sodium fluoride, $K_{i t t}$ rate constant of glucose disappearance, $I L-6$ interleukin-6, $T N F-\alpha$ tumor necrosis factor alpha, HOMA-IR homeostasis model assessment of insulin resistance, $H D L-C$ high-density lipoprotein cholesterol, $V L D L$ very low-density lipoprotein cholesterol, $L D L-C$ low-density lipoprotein cholesterol

cause changes in plasma concentrations of TC, HDL-C, and LDL-C (Table 1).

\section{Insulin Signaling}

In the OVX-C group, there was a significant intra-group difference $(p<0.05)$ in insulin signaling after insulin stimulation. There was a decrease $(p<0.05)$ in the pp185 phosphorylation status, after insulin stimulation, in the white adipose tissue of the OVX-F group compared with the OVX-C group (Fig. 1).

\section{Bone Evaluation of Mineral Density and Microstructure}

The value of the total bone area of the tibia was significantly lower $(p<0.05)$ in the OVX-F group than in the OVX-C group. In addition, the treatment with $\mathrm{NaF}$ did not cause changes either in the bone mineral density or in the bone mineral content (Fig. 2a-c).

Figure 3 shows histomorphometric parameters of the OVX-C and OVX-F groups. The OVX-F group showed a significant decrease $(p<0.05)$ in all parameters analyzed, namely, bone area (B.Ar), trabecular number (Tb.N), and trabecular width ( $\mathrm{Tb} . \mathrm{Wi})$, compared with the controls.
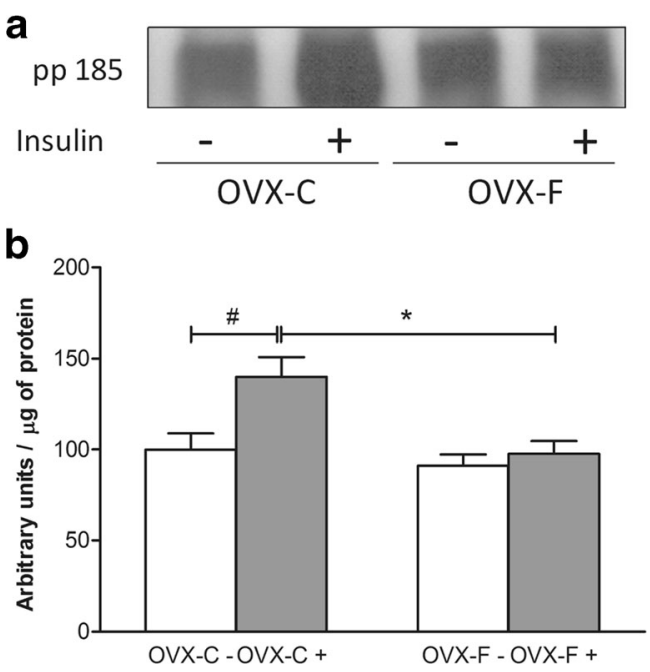

Fig. 1 Insulin-stimulated tyrosine phosphorylation status of pp185 (IRS1/IRS-2) in the white adipose tissue of control ovariectomized rats (OVX$\mathrm{C} ; n=6$ ) and rats treated with sodium fluoride (OVX-F; $n=6$ ). a Typical autoradiograms of white adipose tissue. b Results of the insulinstimulated tyrosine phosphorylation status of pp185 in the white adipose tissue, expressed in arbitrary units per microgram of protein (mean \pm SEM; $n=6$ ). ${ }^{*} p<0.05$ OVX-C (-) vs. OVX-C $(+) ;{ }^{*} p<0.05$ OVX-C (+) vs. OVX-F (+)

\section{Biomechanical Parameters and Assessment of Fluoride Ion Concentration in Bone}

Figure 4 shows the values of (A) stiffness, (B) maximum strength, and $(\mathrm{C})$ tenacity, obtained by 3-point bending flexural tests conducted on the tibia of the animals. Significantly lower values in all three parameters were observed in the OVX-F group.

Figure 5 shows that treatment with $\mathrm{NaF}$ was able to promote a significant increase in fluoride ion concentration in the tibiae of the OVX-F group compared with the OVX-C group.

\section{Immunohistochemical Analysis}

The results obtained from immunohistochemical analysis of the tartrate-resistant acid phosphatase (TRAP) marker are presented in Fig. 6. There was a more intense immunostaining of TRAP in the OVX-F group compared to the control group $(p<0.05)$.

\section{Discussion}

Chronic treatment with NaF-containing drinking water during 42 days promoted insulin resistance and changes in the insulin signaling and bone biomechanical and histomorphometric properties in OVX rats.

The present study showed that chronic treatment with $\mathrm{NaF}$ in OVX rats caused a decrease in the pp185 (IRS-1/IRS-2) tyrosine phosphorylation status in the white adipose tissue, 
Fig. 2 Analysis of bone mineral density emissions by dual X-ray absorptiometry in the control group of ovariectomized rats (OVX-C) and in the group treated with sodium fluoride (OVX-F). a Bone mineral content $(\mathrm{g})$, b total area $\left(\mathrm{cm}^{2}\right)$, and $\mathbf{c}$ bone mineral density $\left(\mathrm{g} / \mathrm{cm}^{2}\right)$. The results are presented as the mean \pm SEM, $n=10 .{ }^{*} p<0.05$ compared with the control group a

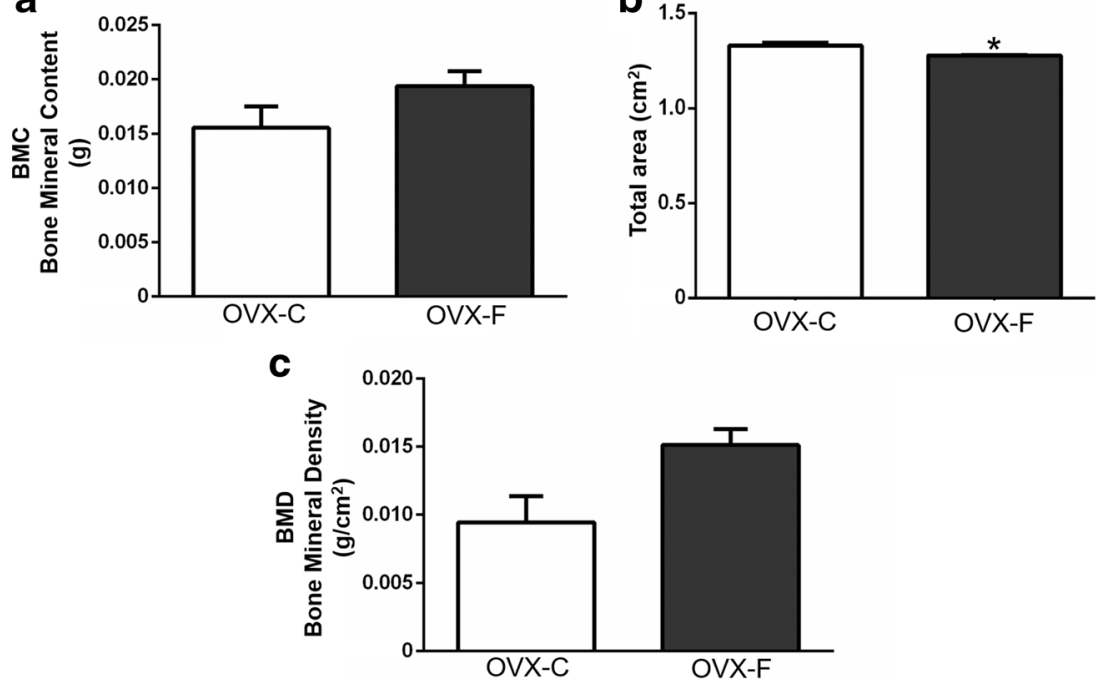

promoting decreased insulin signaling. Previous studies performed in our laboratory, using castrated male rats subjected to a chronic ingestion dosage of $\mathrm{NaF}(4.0 \mathrm{mg} \mathrm{F} / \mathrm{kg}$ body weight/day), showed a reduction in the pp185 tyrosine phosphorylation status in muscle and adipose tissue, resulting in decreased insulin signaling in these tissues $[12,13]$. These
Fig. 3 Microstructure of the proximal tibial metaphysis of control ovariectomized rats (OVX-C group) and rats treated with sodium fluoride (OVX-F group). a, b Photomicrographs showing the histological appearance of cancellous bone in the tibial metaphysis. (c, f) Graphics showing mean \pm SEM $(n=10)$ of the bone morphometric parameters; c percentage of bone in the analyzed area; $\mathbf{d}$ cancellous bone area (B.Ar); e trabecular number (Tb.N); and $\mathbf{f}$ trabecular width (Tb.Wi). bt trabecular bone; $* p<0.05$ compared with the control group; stain hematoxylin and eosin. Original magnification $-\times 250$. Scale bars $-100 \mu \mathrm{m}$
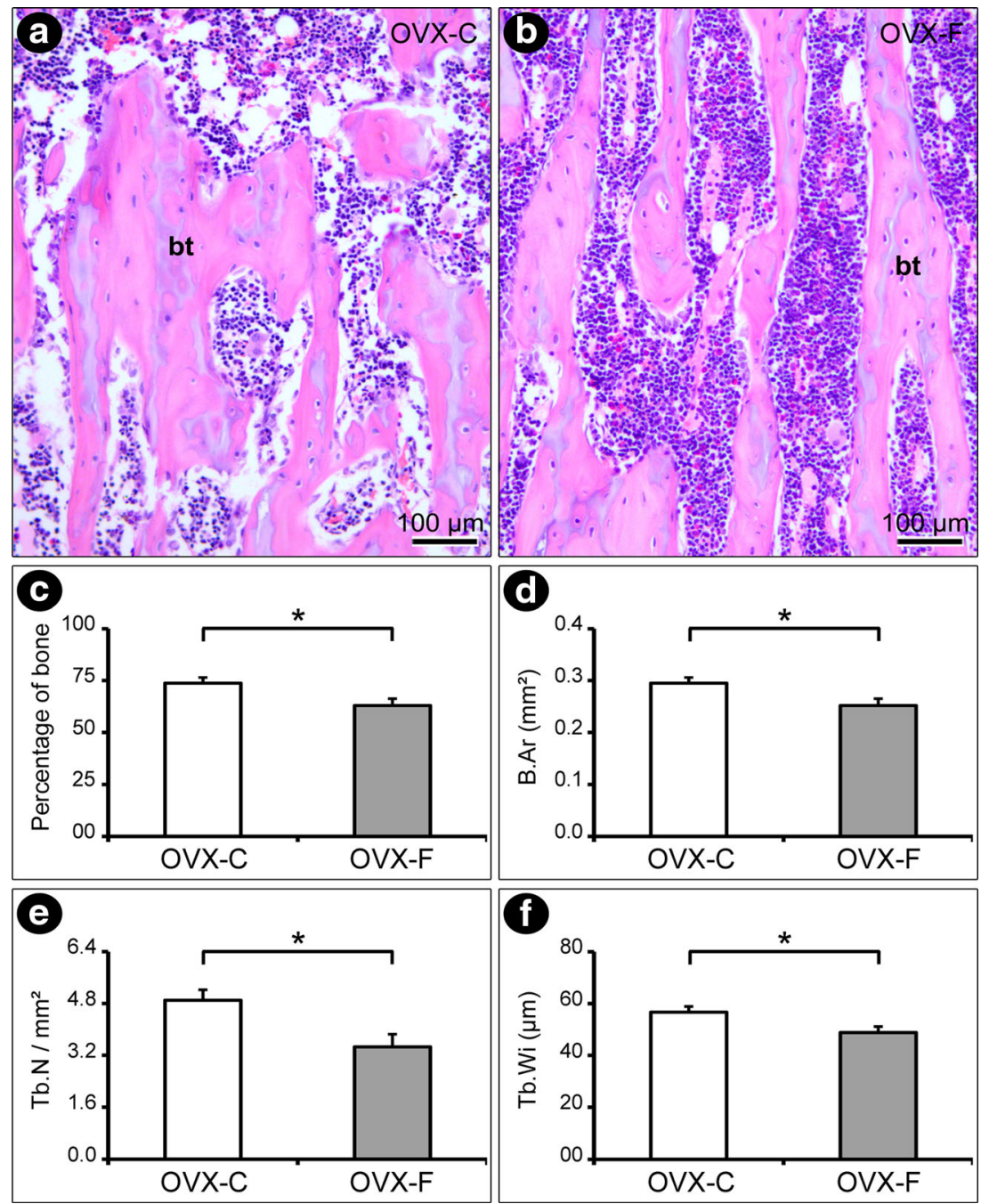


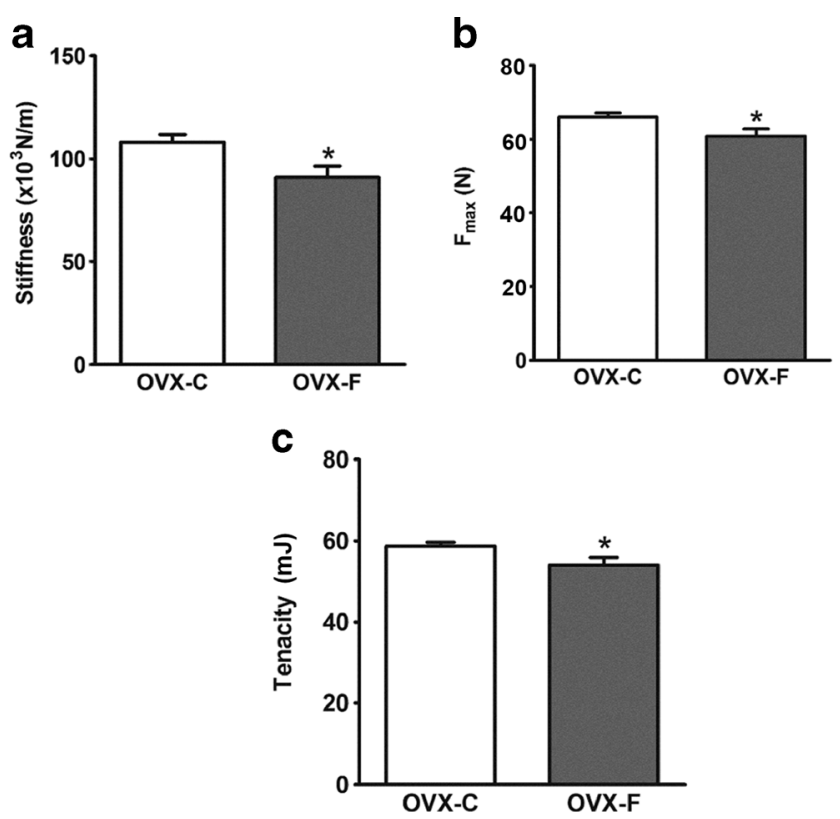

Fig. 4 Biomechanical properties of tibiae of ovariectomized rats from the control (OVX-C) group and sodium-fluoride-treated (OVX-F) group, evaluated by the 3-point bending test. a Extrinsic stiffness $\left(\times 10^{3} \mathrm{~N} / \mathrm{m}\right)$; b $F_{\max }(\mathrm{N})$, maximum strength; and $\mathbf{c}$ tenacity $(\mathrm{mJ})$. The results are presented as the mean \pm SEM, $n=10 .{ }^{*} p<0.05$ compared with the control group

responses suggest that fluoride can cause insulin resistance, because several authors correlated insulin resistance with a decrease in insulin signaling [12, 27-29].

The treatment with $\mathrm{NaF}$ promoted an increase in the plasma insulin concentration in the OVX-F group, but no difference in blood glucose was observed between the groups. This increase in insulin may be attributed to a response of the animal to the decrease in glucose uptake by the cells due to insulin resistance, making it necessary for the pancreas to increase its production of insulin in order to maintain a normal blood glucose concentration [30]. From the values of glycemia and insulinemia, the HOMA-IR index, which expresses the insulin resistance, was calculated. The value of this index was higher in the OVX-F group than in the OVX-C group, demonstrating that treatment with $\mathrm{NaF}$ induced insulin resistance. The results

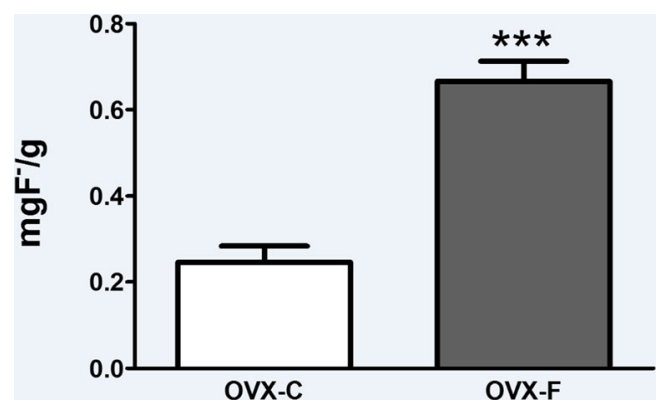

Fig. 5 Fluoride ion concentration ( $\mathrm{mgF} / \mathrm{g}$ of tissue) in tibiae of the control (OVX-C) group and sodium-fluoride-treated (OVX-F) group of ovariectomized rats. Values are presented as the mean $\pm \mathrm{SEM}, n=10$. $* p<0.05$ compared with the control group of this study also demonstrated that the rate constant for glucose disappearance $\left(K_{\mathrm{itt}}\right)$ in the OVX-F group was reduced relative to that in the controls, reinforcing that the OVX-F group is insulin resistant.

Studies performed in normoglycemic men with insulin resistance have shown that cholesterol synthesis is increased in these patients. Insulin resistance and type 2 diabetes mellitus have been consistently associated with high plasma concentrations of TGs and low plasma concentrations of HDL-C. The increased synthesis of VLDL-C in the liver appears to be the main cause of increased concentrations of TG-rich lipoproteins. This excess of VLDL-C and TG in the liver is associated with elevated plasma levels of fatty acids in patients with insulin resistance [31]. The results of this study showed that treatment with $\mathrm{NaF}$ promoted an increase in plasma concentrations of TG and VLDL-C.

Graham et al. [32] showed that rats fed with a hyperlipidic diet developed osteopenia. They investigated in vitro the involvement of $\mathrm{T}$ lymphocytes from the bone marrow of these animals and observed an increase of several cytokines, including TNF- $\alpha$, IL- 6 , and receptor activator of nuclear factor kappa-B ligand. From these results, they suggested that $\mathrm{T}$ lymphocytes play a key role in diet-induced osteoclastogenesis and can contribute to the bone loss associated with osteopenia. The results of the present study showed higher levels of plasma TNF- $\alpha$ and IL-6 in ovariectomized rats treated with NaF. Chiba et al. [11] have shown that administration of $\mathrm{NaF}$ to castrated male rats promoted insulin resistance and increased the plasma concentration of TNF- $\alpha$. The results of this study are thus in agreement with the results of Chiba et al. [11]. Peraldi and Spiegelman [33] suggested that TNF- $\alpha$ may alter the insulin signal transmission by increasing IRS- 1 serine phosphorylation. The phosphorylated IRS-1 serine inhibits the tyrosine kinase activity of the insulin receptor, thereby reducing insulin signaling [34].

In the obesity condition, macrophages produce high levels of TNF- $\alpha$ and IL- 6 that promote osteoclast activity, leading to bone resorption [35]. IL-6 is a cytokine that can affect bone mass. The chronic expression of IL-6 increases bone remodeling and causes the loss of bone mass by increasing its reabsorption [36].

The results of this study showed an increase in plasma calcium levels in the OVX-F group. It is known that osteoporosis in women is associated with a decrease of estrogen, which accelerates bone loss. There are other mechanisms that can lead to hypercalcemia, such as an increase in bone resorption and in intestinal calcium absorption and a decrease in the urinary excretion of calcium [37]. Studies performed with osteoblasts (MC3T3-E1) treated with calcium and fluoride in vitro showed that L-type calcium channels play an important role in this mineral homeostasis, because they affect the osteogenic expression of transcription factors such as activator protein 1 , runt-related transcription factor 2 , and osterix in 
Fig. 6 TRAP immunolabeling. Photomicrographs showing immunolabeling cell in the proximal tibial metaphysis of a control ovariectomized rats (OVX-C group) and $\mathbf{b}$ rats treated with sodium fluoride (OVX-F group). Black arrows represent the TRAP-positive cells. Counterstaining-hematoxylin. Original magnification $-\times 160$. Scale bars- $100 \mu \mathrm{m}$
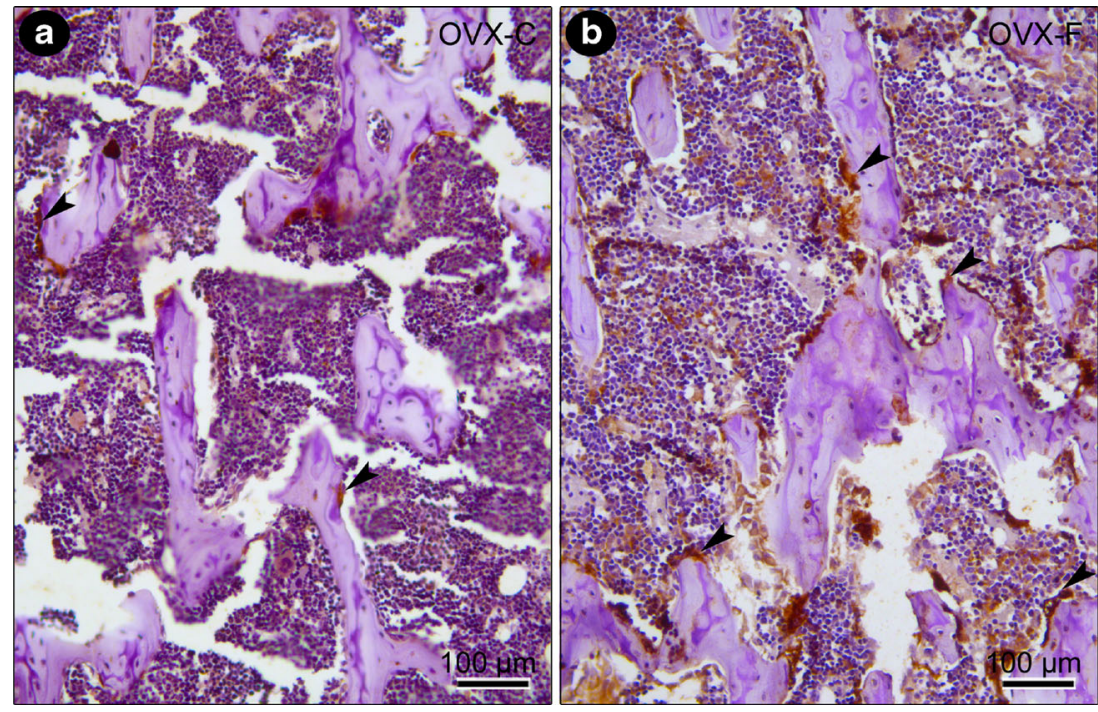

osteoblasts exposed to a low concentration $(2.0 \mathrm{mg} / \mathrm{L})$ of fluoride. These results suggest that the regulation of the expression or activity of the L-type calcium channels can regulate calcium signaling in bone cells and the modulation of these channels can influence bone remodeling in conditions of fluorosis [38].

Dandona et al. [39] performed a study in healthy men undergoing treatment with sodium fluoride for 3 weeks, and their serum osteocalcin concentrations were measured before, during, and after 3 weeks of the treatment. Results showed increased plasma concentrations of this substance at the end of the treatment. These researchers concluded that fluoride administration in normal individuals during a short period of time increases the serum osteocalcin level. Our results are in agreement with these data, because it was observed that the OVX-F group had higher plasma concentrations of osteocalcin than the control group. Osteocalcin-knockout mice exhibit increased blood glucose and decreased insulin compared with wild-type mice [40]. In this study, it was also found that the insulin secretion and sensitivity to this hormone were reduced in these mice knocked out for osteocalcin. The increased plasma osteocalcin may also have promoted an increase in plasma insulin in the OVX-F group. On the other hand, in our studies, this increase in plasma osteocalcin did not increase insulin sensitivity. In fact, the insulin sensitivity got worse. This response may be because $\mathrm{NaF}$ promotes an increased concentration of TNF- $\alpha$, which in turn promotes insulin resistance [11]. In relation to insulin sensitivity, the effect of this cytokine seems to overcome the effect of osteocalcin in this hormone sensitivity.

Animals in the OVX-F group in this study experienced a decrease in total bone area, but there was no change in the bone mineral content and bone mineral density. There is not always a direct correlation between the occurrence of fractures and the densitometry results. Densitometry measures the calcified bone mass, but not the quality of this bone mass. Some clinical studies have demonstrated that the use of fluoride for the treatment of osteoporosis increases the bone mineral density but does not decrease the risk of vertebral fracture $[8,41-43]$.

A biomechanical study showed a decrease in bone quality in rats treated with fluorine doses of 100 and $150 \mathrm{ppm}$ for 90 days [44]. The results of our present study are in agreement with Søgaard et al. [45], who also observed a decrease in all the biomechanical parameters in the bones of F-treated OVX rats.

Fernandes et al. [46] performed studies with rats treated with variable doses of $\mathrm{NaF}$ administered in drinking water and observed that a dose of 5 ppm fluoride ion did not promote any change in bone formation, whereas the dose of $50 \mathrm{ppm}$ promoted damage in bone formation. The results of TRAP immunostaining corroborate the data of Fernandes et al. [46] that observed an increase in TRAP expression in bone cells treated with $50 \mathrm{ppm}$ of fluoride. The immunostaining of TRAP is an important marker for the characterization of osteoclast activity, and its higher expression can be related to decreased bone area.

The results of this study also showed impairments in the histomorphometric and biomechanical parameters of the bone. A condition of bone fragility was observed, which was verified by the decrease of maximum strength in the tibia of the OVX-F group compared with the control group. In addition, there was a decrease in the bone area, trabecular number, and trabecular width. Grey et al. [4] observed that patients treated with placebo or a low dose of fluoride (2.5, 5 , and $10 \mathrm{mg} /$ day) for 1 year did not show significant changes of the skeleton and concluded that therapy with $\mathrm{NaF}$ is ineffective for the treatment of osteoporosis.

Shin et al. [47], in a study performed in men, investigated the association between insulin resistance and bone mineral 
density, and it was observed that insulin resistance is a negative predictor of bone health. In addition, the association between insulin level and bone mineral density changed according to the degree of insulin resistance, that is, when the individual is more insulin resistant, the bone mass decreases.

Based on these results, we conclude that treatment with a high dose of $\mathrm{NaF}$ did not promote changes in bone mineral density, but it did decrease biomechanical and histomorphometric parameters in the tibia, demonstrating that this treatment promoted the formation of bone of a lower quality. Furthermore, the NaF promoted reductions in insulin signaling and insulin resistance. We emphasize that this hormone resistance worsens with aging. Therefore, the use of $\mathrm{NaF}$ for the treatment of osteoporosis should be done cautiously, especially in women post menopause.

Acknowledgments This work was supported by funds from the Coordination of Improvement of Higher Education Personnel (CAPES), Pro-rector for research, and graduate of UNESP- Univ Estadual Paulista, Brazil.

\section{Compliance with Ethical Standards}

Conflicts of interest The authors declare that they have no conflicts of interest.

\section{References}

1. Veldhuis-Vlug AG, Fliers E, Bisschop PH (2013) Bone as a regulator of glucose metabolism. Neth J Med 71:396-400

2. Bonucci E, Ballanti P (2013) Osteoporosis: bone remodeling and animal models. Toxicol Pathol 000:1-13

3. Schnitzler CM, Solomon L (1985) Trabecular stress-fractures during fluoride therapy for osteoporosis. Skelet Radiol 14:276-279

4. Grey A, Garg S, Dray M, Purvis L, Horne A, Callon K, Gamble G, Bolland M, Reid IR, Cundy T (2013) Low-dose fluoride in postmenopausal women: a randomized controlled trial. J Clin Endocrinol Metab 98:2301-2307

5. Carvalho CRO, Brenelli SL, Silva AC, Nunes ALB, Velloso LA, Saad MJA (1996) Effect of aging on insulin receptor, insulin receptor substrate-1, and phosphatidylinositol 3-kinase in liver and muscle of rats. Endocrinology 137:151-159

6. Román LDA, de la Fuente AR, de Luis J, Pérez JL, González M (2004) Papel del flúor en la osteoporosis. Endocrinologia y Nutrición 1:426-432

7. Jiang Y, Zhao J, Van Audekercke R, Dequeker J, Geusens P (1996) Effects of low-dose long-term sodium fluoride preventive treatment on rat bone mass and biomechanical properties. Calc Tissue Int 58: 30-39

8. Riggs BL, Hodgson SF, Ofallon WM, Chao EYS, Wahner HW, Muhs JM, Cedel SL, Melton LJ (1990) Effect of fluoride treatment on the fracture rate in postmenopausal women with osteoporosis. $\mathrm{N}$ Engl J Med 322:802-809

9. Trivedi N, Mithal A, Gupta SK, Godbole MM (1993) Reversible impairment of glucose-tolerance in patients with endemic fluorosis. Diabetologia 36:826-828
10. Grucka-Mamczar E, Birkner E, Kasperczyk S, Kasperczyk A, Chlubek D, Samujlo D, Ceglowska A (2004) Lipid balance in rats with fluoride-induced hyperglycemia. Fluoride 37:195-200

11. Chiba FY, Colombo NH, Shirakashi DJ, da Silva VC, Saliba Moimaz SA, Saliba Garbin CA, Antoniali C, Sumida DH (2012) $\mathrm{NaF}$ treatment increases TNF-alpha and resistin concentrations and reduces insulin signal in rats. J Fluoride Chem 136:3-7

12. Chiba FY, Colombo NH, Shirakashi DJ, de Souza Gomes WD, Saliba Moimaz SA, Saliba Garbin CA, Silva CA, Sumida DH (2010) Insulin signal decrease in muscle but not in the liver of castrated male rats from chronic exposure to fluoride. Fluoride 43: 25-30

13. Chiba FY, Saliba Garbin CA, Sumida DH (2012) Effect of fluoride intake on carbohydrate metabolism, glucose tolerance, and insulin signaling. Fluoride 45:236-241

14. Farley JR, Wergedal JE, Baylink DJ (1983) Fluoride directly stimulates proliferation and alkaline phosphatase activity of boneforming cells. Science 222:330-332

15. Chehoud KA, Chiba FY, Sassaki KT, Saliba Garbin CA, Sumida DH (2008) Effects of fluoride intake on insulin sensitivity and insulin signal transduction. Fluoride 41:270-275

16. Rigalli A, Ballina JC, Roveri E, Puche RC (1990) Inhibitory effect of fluoride on the secretion of insulin. Calc Tissue Int 46:333-338

17. Claro FA, Sa Lima JR, Salgado MAC, Gomes MF (2005) Porous polyethylene for tissue engineering applications in diabetic rats treated with calcitonin: histomorphometric analysis. Int J Oral Maxillofac Implants 20:211-219

18. Bonora E, Targher G, Alberiche M, Bonadonna RC, Saggiani F, Zenere MB, et al. (2000) Homeostasis model assessment closely mirrors the glucose clamp technique in the assessment of insulin sensitivity: studies in subjects with various degrees of glucose tolerance and insulin sensitivity. Diabetes Care 23:57-63

19. Friedewald WT, Levy RI, Fredrickson DS (1972) Estimation of the concentration of low-density lipoprotein cholesterol in plasma, without use of the preparative ultracentrifuge. Clin Chem 18:499502

20. Taves DR (1968) Separation of fluoride by rapid diffusion using hexamethyldisiloxane. Talanta 15:969-974

21. Whitford GM (1996) The metabolism and toxicity of fluoride. Karger

22. Buzalaf MAR, Fuhushima R, Granjeiro JM, Cury JA (2002) Correlation between plasma and nail fluoride concentrations in rats given different levels of fluoride in water. Fluoride 35:185-192

23. Rigalli A, Alloatti R, Puche RC (1999) Measurement of total and diffusible serum fluoride. J Clin Lab Anal 13:151-157

24. Shirakashi DJ, Leal RP, Colombo NH, Chiba FY, Garbin CAS, Jardim EG, Antoniali C, Sumida DH (2013) Maternal periodontal disease in rats decreases insulin sensitivity and insulin signaling in adult offspring. J Periodontol 84:407-414

25. Dempster DW, Compston JE, Drezner MK, Glorieux FH, Kanis JA, Malluche H, Meunier PJ, Ott SM, Recker RR, Parfitt AM (2013) Standardized nomenclature, symbols, and units for bone histomorphometry: a 2012 update of the report of the ASBMR Histomorphometry Nomenclature Committee. J Bone Miner Res 28:1-16

26. Pedrosa WF Jr, Okamoto R, Faria PE, Arnez MF, Xavier SP, Salata LA (2009) Immunohistochemical, tomographic and histological study on onlay bone graft remodeling. Part II: Calvarial Bone Clin Oral Implants Res 20:1254-1264

27. Kasuga M, Hedo JA, Yamada KM, Kahn CR (1982) The structure of insulin receptor and its subunits. evidence for multiple nonreduced forms and a 210,000 possible proreceptor. J Biol Chem 257:10392-10399

28. Chou CK, Dull TJ, Russell DS, Gherzi R, Lebwohl D, Ullrich A, Rosen OM (1987) Human insulin receptors mutated at the ATP- 
binding site lack protein tyrosine kinase activity and fail to mediate postreceptor effects of insulin. J Biol Chem 262:1842-1847

29. Ebina Y, Araki E, Taira M, Shimada F, Craik CS, Siddle K, Pierce SB, Roth RA, Rutter WJ (1987) Replacement of lysine residue 1030 in the putative ATP-binding region of the insulin receptor abolishes insulin- and antibody-stimulated glucose uptake and receptor kinase activity. Proc Natl Acad Sci U S A 84:704-708

30. Cesaretti MLR, Kohlmann OJ (2006) Modelos experimentais de resistência à insulina e obesidade: lições aprendidas. Arq Bras Endocrinol Metabol 50:190-197

31. Pihlajamäki J, Gylling H, Miettinen TA, Laakso M (2004) Insulin resistance is associated with increased cholesterol synthesis and decreased cholesterol absorption in normoglycemic men. J Lipid Res 45:507-512

32. Graham LS, Tintut Y, Parhami F, Kitchen CM, Ivanov Y, Tetradis S, Effros RB (2010) Bone density and hyperlipidemia: the Tlymphocyte connection. J Bone Miner Res 25:2460-2469

33. Peraldi P, Spiegelman B (1998) TNF-alpha and insulin resistance: summary and future prospects. Mol Cell Biochem 182:169-175

34. Hotamisiligil GS, Peraldi P, Budavari A, Ellis R, White MF, Spiegelman BM (1996) IRS-1-mediated inhibition of insulin receptor tyrosine kinase activity in TNF-alpha and obesity-induced insulin resistance. Science 271:665-668

35. Kobayashi K, Takahashi N, Jimi E, Udagawa N, Takami M, Kotake S, Nakagawa N, Kinosaki M, Yamaguchi K, Shima N, Yasuda H, Morinaga T, Higashio K, Martin TJ, Suda T (2000) Tumor necrosis factor alpha stimulates osteoclast differentiation by a mechanism independent of the ODF/RANKL-RANK interaction. J Exp Med 191:275-285

36. de Benedetti F, Rucci N, del Fattore A, Peruzzi B, Paro R, Longo M, Vivarell M, Muratori F, Berni S, Ballanti P, Ferrari S, Teti A (2006) Impaired skeletal development in interleukin-6-transgenic mice - a model for the impact of chronic inflammation on the growing skeletal system. Arthritis Rheum 54:3551-3563

37. Martin LNC, Kayath MJ (1999) Abordagem clínico-laboratorial no diagnóstico diferencial de hipercalcemia. Arq Bras Endocrinol Metab 43:472-479
38. Duan XQ, Zhao ZT, Zhang XY, Wang Y, Wang H, Liu DW, Li GS, Jing L (2014) Fluoride affects calcium homeostasis and osteogenic transcription factor expressions through l-type calcium channels in osteoblast cell line. Biol Trace Elem Res 162:219-226

39. Dandona P, Coumar A, Gill DS, Bell J, Thomas M (1988) Sodium fluoride stimulates osteocalcin in normal subjects. Clin Endocrinol 29:437-441

40. Lee NK, Sowa H, Hinoi E, Ferron M, Ahn JD, Confavreux C, Dacquin R, Mee PJ, Mckee MD, Jung DY, Zhang Z, Kim JK, Mauvais-Jarvis F, Ducy P, Karsenty G (2007) Endocrine regulation of energy metabolism by the skeleton. Cell 130:456469

41. Dambacher MA, Ittner J, Ruegsegger P (1986) Long-term fluoride therapy of postmenopausal osteoporosis. Bone 7:199-205

42. Kleerekoper M, Peterson EL, Nelson DA, Phillips E, Schork MA, Tilley BC, Parfitt AM (1991) A randomized trial of sodium fluoride as a treatment for postmenopausal osteoporosis. Osteoporos Int 1: $155-161$

43. Haguenauer D, Welch V, Shea B, Tugwell P, Adachi JD, Wells G (2000) Fluoride for the treatment of postmenopausal osteoporotic fractures: a meta-analysis. Osteoporos Int 11:727-738

44. Søgaard CH, Mosekilde L, Schwartz W, Leidig G, Minne HW, Ziegler R (1995) Effects of fluoride on rat vertebral body biomechanical competence and bone mass. Bone 16:163-169

45. Søgaard CH, Mosekilde L, Thomsen JS, Richards A, Mcosker JE (1997) A comparison of the effects of two anabolic agents (fluoride and PTH) on ash density and bone strength assessed in an osteopenic rat model. Bone 20:439-449

46. Fernandes MS, Yanai MM, Martins GM, Iano FG, Leite AL, Cestari TM, Taga R, Buzalaf MAR, Oliveira RC (2014) Effects of fluoride in bone repair: an evaluation of RANKL, OPG and TRAP expression. Odontology 102:22-30

47. Shin D, Kim S, Kim KH, Lee K, Park SM (2014) Association between insulin resistance and bone mass in men. J Clin Endocrinol Metab 99:988-995 